\title{
SPATIAL PATTERNS OF BIODIVERSITY-ASSESSING VEGETATION USING HEXAGONAL GRIDS
}

\author{
Gerald Jurasinski and Carl Beierkuhnlein
}

Gerald Jurasinski (corresponding author e-mail: gerald.jurasinski@ uni-bayreuth.de) and Carl Beierkuhnlein, Department of Biogeography, University of Bayreuth, 95440 Bayreuth, Germany.

\begin{abstract}
We still lack quantitative and comprehensive methods to assess spatio-temporal changes in biodiversity of landscapes. Even more, we need methods to determine the amounts of change especially in the light of the current acceleration in the loss of biodiversity.

We have developed a widely applicable method to reveal spatio-temporal changes in vegetation patterns and relate them to ecosystem processes. We use a systematic grid of hexagonal plots in a spatially nested design (three spatial scales and levels) to examine these patterns. The hexagonal grid, as well as the hexagonal plot, provides several advantages compared to other methods. Most important in the context of evaluating patterns is the equidistant nature of the grid. This facilitates data analysis and circumvents statistical and logical problems (compared to squared or circular plots). Correlation is very strong $\left(r=0.88^{\star \star}\right)$ between structural data assessed with the line-intercept method and that gathered from field sketches. This indicates that the lines used to mark out the plots provide an easy and feasible method to assess quantitative data on structure and disturbance. We show that frequency data does not perform better than presence-absence data regarding correlation with other variables. We conclude that the hexagonal grid provides an efficient method to assess patterns of biodiversity.
\end{abstract}

\section{INTRODUCTION}

Land use and land-use changes are among the main drivers of biodiversity loss (e.g. Austrheim et al. 1999; Crist et al. 2000; Sala et al. 2000; Allan et al. 2002). However, changes are often difficult to measure; individuals of a species may still be found flowering although the population has been in decline for decades and has only survived with a few over-aged specimens on a small remnant area. Furthermore, populations often change their geographic occurrence or their density in a given region. There are hardly any reliable methods to assess and track such changes.

In general, recent literature on the influence of global change on biodiversity focuses either on the human-environmental system (very large scale and meta data analysis, e.g. Ayres and Lombardero 2000; Hannah et al. 2002; de Vries et al. 2003) or on specific organisms or even organic responses to climate change (very small scale and mostly experimental, e.g. Constable et al. 1999; Bermejo et al. 2002; Hättenschwiler and Körner 2003; Körner 2003). Information about shifts in community composition at a medium scale (landscape, ecosystem, habitat) is scarce (e.g. Gottfried et al. 1998). Hence, we need spatially and temporarily explicit and widely applicable methods giving comparable results to widen our understanding of these processes as well as to monitor changes in biodiversity on a medium scale to predict long-term responses of ecosystems to environmental change.

Even though a comprehensive concept of biodiversity encompasses more than just species diversity, a lot of research is still based on species richness (alpha diversity) as a measure of diversity (e.g. Tilman and Elhaddi 1992; Schulze and Mooney 1993; Krishnamani et al. 2004). Even the large body of literature that deals with the implications of biodiversity for ecosystem function (e.g. Grime 1998; Bednekoff 2001; Hart et al . 2001) focuses largely on alpha diversity. The same holds true for literature on emerging patterns of vegetation (Richerson and Lum 1980; Addicott et al. 1987; Olsvig-Whittaker 1988; Cracraft 1992; Araújo 1999; Lister et al. 2000). There are only a few studies which actually apply parts of a comprehensive concept of biodiversity (including similarity/dissimilarity and functional diversity) in ecological field studies (e.g. van der Maarel 1976; Pitkänen 1998; De'ath 1999; Kluth and Bruelheide 2004). The concentration just on species numbers may, inter alia, indicate a lack of methodological applications of an extended biodiversity concept.

Our aim is to develop a spatially explicit, widely applicable method to assess phytodiversity encompassing species richness, spatial and temporal heterogeneity and functional diversity and to relate 
it to environmental conditions (including site conditions and disturbance regime). There is an urgent need for standardised and comparable data in order to detect changes of biodiversity. Such methods are required to be representative as well as pragmatic due to the simple fact that there is insufficient time to obtain complete data sets relating to temporal trends. If biodiversity is lost rapidly at the landscape level, frequent re-investigations have to be done in order to detect and analyse such changes. Thus, our objective is to provide a method that allows for the tracking of changes in biodiversity at the landscape scale. In this communication we focus on methodological aspects of our work. We will answer the following questions on the basis of field data recorded in a recent study in north-eastern Morocco: 1) is the hexagonal plot suitable for an easy and efficient assessment of structural variables? 2) is there any benefit in assessing frequency values (compared to presence absence data)?

\section{MATERIALS AND METHODS}

\section{SITE DESCRIPTION}

The investigation area is situated at $34^{\circ} \mathrm{N}$ and $3^{\circ} \mathrm{W}$ at the edge of the north-eastern Moroccan high plateau (Plateau du Rekkam) about $100 \mathrm{~km}$ from both the Algerian border and the Mediterranean Sea. It lies at an altitude of between $1550 \mathrm{~m}$ and $1670 \mathrm{~m}$ a.s.1. The Gaada de Debdou, which marks the brim of the Plateau du Rekkam, is situated in an exceptional orographic position. It receives about $500 \mathrm{~mm}$ of precipitation a year, which is far more than the Plateau itself (which receives about $200 \mathrm{~mm}$ a year). This allows evergreen forests to grow. On the edge of the plateau these forests consist mainly of Quercus rotundifolia L (stone oak). The nomenclature of the plant species follows Valdés et al. (2002). On the slopes Pinus halepensis Mill. (Aleppo pine) and Tetraclinis articulata (Vahl) Masters (gum juniper) are the main species. On the plateau, where most of the sampling was done, only Juniperus oxycedrus L. ssp oxycedrus (prickly juniper) occurs with the stone oak.

The principal anthropogenic influence is grazing with sheep and goats by semi-nomadic families. Because of the favourable climatic conditions the herds can graze over a long period even when food becomes scarce in regions further east on the plateau (Dhara) or in the western plains (Moulouya Valley). Consequently, the nomads remain longer at the Gaada than elsewhere in the region as long as conditions are favourable for grazing.

\section{SAMPLING DESIGN}

We implemented a spatially nested hexagonal sampling grid that provides several advantages compared to other methods. Systematic sampling means that sampling locations are objectively chosen, thus minimising the influence of subjective decisions (Traxler 1998) that might be a problem with preferential and even random sampling (Colbach et al. 2000). Compared to systematic sampling, random sampling was often found to be less efficient (e.g. Austin 1981; Kipfmueller and Baker 1998; Singer et al. 2002; Higgins and Ruokolainen 2004). Additionally systematic sampling is the best choice when looking for spatial patterns (Cole et al. 2001).

In the hexagonal grid all adjacent plots are the same distance from each other and there is no overlap when comparing neighbouring sampling units (see Fig. 1). These are important prerequisites when using similarity indices to calculate spatial patterns to avoid problems with spatial autocorrection. Moreover, we decided to use hexagonal plots for reasons of consistency and to minimise perimeter:area ratio. Circles would be ideal in this regard, but they need more effort and are more complicated to set up in the field, especially when working in woody vegetation.

The proposed hexagonal sampling grid consists of three nested scale levels. With data recorded at different levels we can detect the scale at which disturbance-driven patterns emerge in vegetation. The hierarchical, spatially nested design is shown in Fig. 2. The arrangement of the grid is the same at all levels and consists of nineteen equidistant sample cells. To investigate the influence of distance on spatial patterns of plant diversity the top level is replicated at three distance levels. Some of the plots belong to more than one level, thus providing an efficient method to evaluate the influence of grain and extent on spatial patterns of biodiversity (see Nekola and White (1999) for a comprehensive review on the importance of scale in ecological analyses). It also facilitates the investigation of the different drivers that determine the patterns at the various scales.

The sample plot is the main level of investigation. Data from the sample plots are scaled up to provide information on the plot. It is not possible to sample all sampling locations because this would result in 15,523 sampling points. Therefore, only parts of the grid have been sampled completely at all levels, (i.e. all sample plots in a plot and all sub-plots in a sample plot) to enable the analysis of spatial patterns at these scales, while elsewhere only randomly chosen plots inside the bigger units have been sampled.

Spatial patterns of beta-diversity are calculated through the computing of similarity measures (such as Sørensen-Index (Sørensen 1948) or 

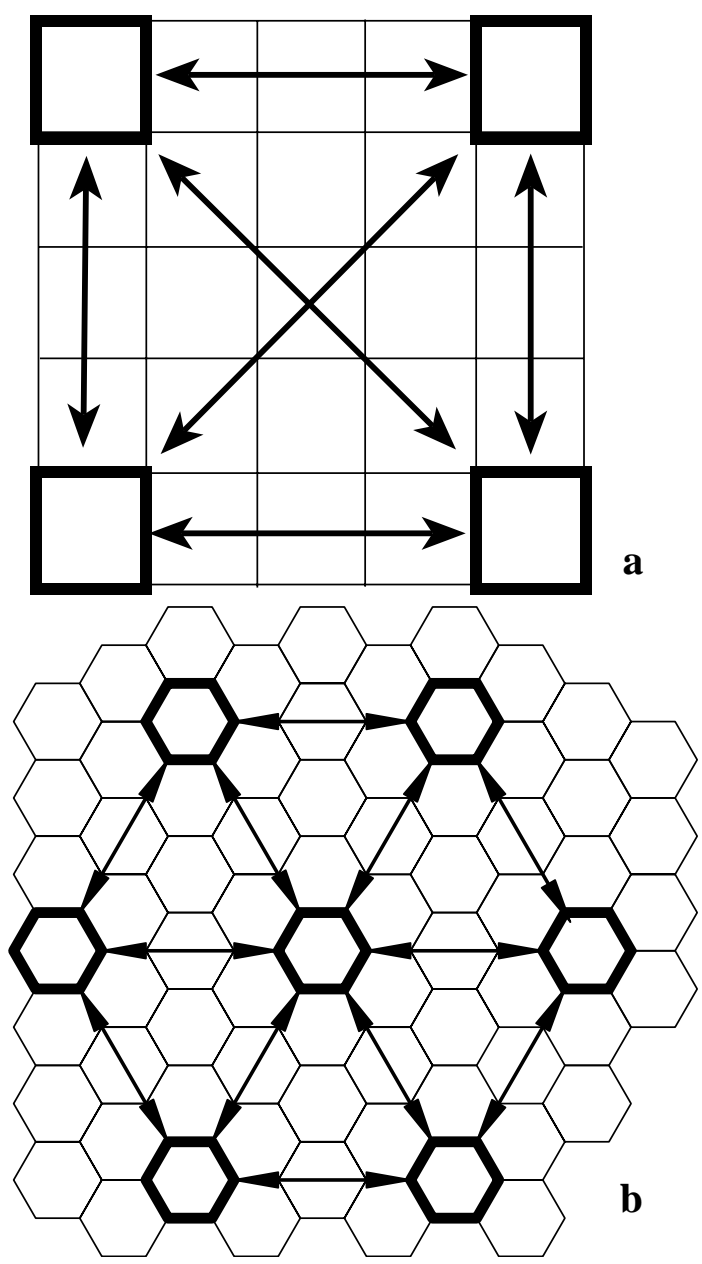

Fig. 1-(a) In a square grid the adjacent plots are not equidistant. Furthermore similarities calculated between different plots occur in one place (crossing diagonals). To calculate a mean of those is not acceptable. (b) In a hexagonal (or triangular) grid all adjacent neighbours are equidistant. All calculated similarity (or dissimilarity) values are unique.

Jaccard-Index (Jaccard 1912)) and distance measures (e.g. Bray-Curtis distance (Bray and Curtis 1957)) depending on data properties. For the characterisation and evaluation of spatial patterns values between neighbouring cells have been computed. For information regarding the general spatial structure of the area investigated (e.g. via semi-variograms, or correlograms) the values between all recorded sample plots were calculated.

\section{DATA RECORDING}

At the sample locations, data on vegetation, site conditions, structure and disturbance were recorded to different extents, depending on the scale level. Here we will focus on data used to answer methodological questions. These were recorded at sample plot scale. Navigation to the sample plots was done using GPS-Devices (Leica GS20 for exact marking of the sample plots; a Garmin gpsmap 76a was used later when revisiting sites). The centre of the sample plot was marked initially with a magnet to facilitate repetitions at exactly the same place. Starting with a north-facing triangle the sample plot is marked out in the field using twelve ropes of $8 \mathrm{~m}$ length so that all the sample plots are oriented to the north.

To begin, a comprehensive description of the sample plot was made. The severity of disturbance was categorised based on hoof marks, faeces of goats and sheep, grazing signs and the distance to tracks and tents (using GIS). Aspect, slope, elevation and relief were recorded to characterise the sites. The soil was classified in the field using the German Soil Classification System (Bodenkundliche Kartieranleitung 4, A.G. Boden 1996), and a soil sample was taken for later analysis of $\mathrm{pH}, \mathrm{C} / \mathrm{N}$ ratio, and conductivity in the laboratory of the University in Bayreuth. The depth of the A horizon, soil type, stone and gravel content, presence of roots and humus, bulk density and topsoil texture were also recorded.

The presence of higher plant species was recorded, unknown species being collected for further determination in Bayreuth. For efficiency and in order to simplify the process, species abundance was not recorded. This means less but more reliable information because the estimation of abundance might be vulnerable to subjective errors (Tüxen 1972; Leps 1992). More exact approaches, such as the point quadrat method, are too timeconsuming, especially for species with low abundance (Goodall 1952; Everson et al. 1990), which make up the majority of the species in our samples.

\section{ASSESSING STRUCTURES}

To evaluate the possibility of assessing quantitative data on vegetation structure using the line-intercept method (e.g. Mueller-Dombois and Ellenberg 1974), detailed sketches of the sample plots, including the shape and cover of bushes and trees, the location of fire-sites, rocks and several other features were made in 125 sample plots during the 2003 field season. The quality and precision of the sketches is very high because they were drawn on a copied template (scale 1:100) of the hexagonal plot, which formed part of the field checklist. Furthermore, the ropes provided a means for a projection of recorded features on points along the line, thus increasing the accuracy of the sketches.

The proportions of bare soil and stones as well as the cover of trees, bushes and Asphodelus microcarpa DC were recorded using the lineintercept method. Asphodelus was recorded 


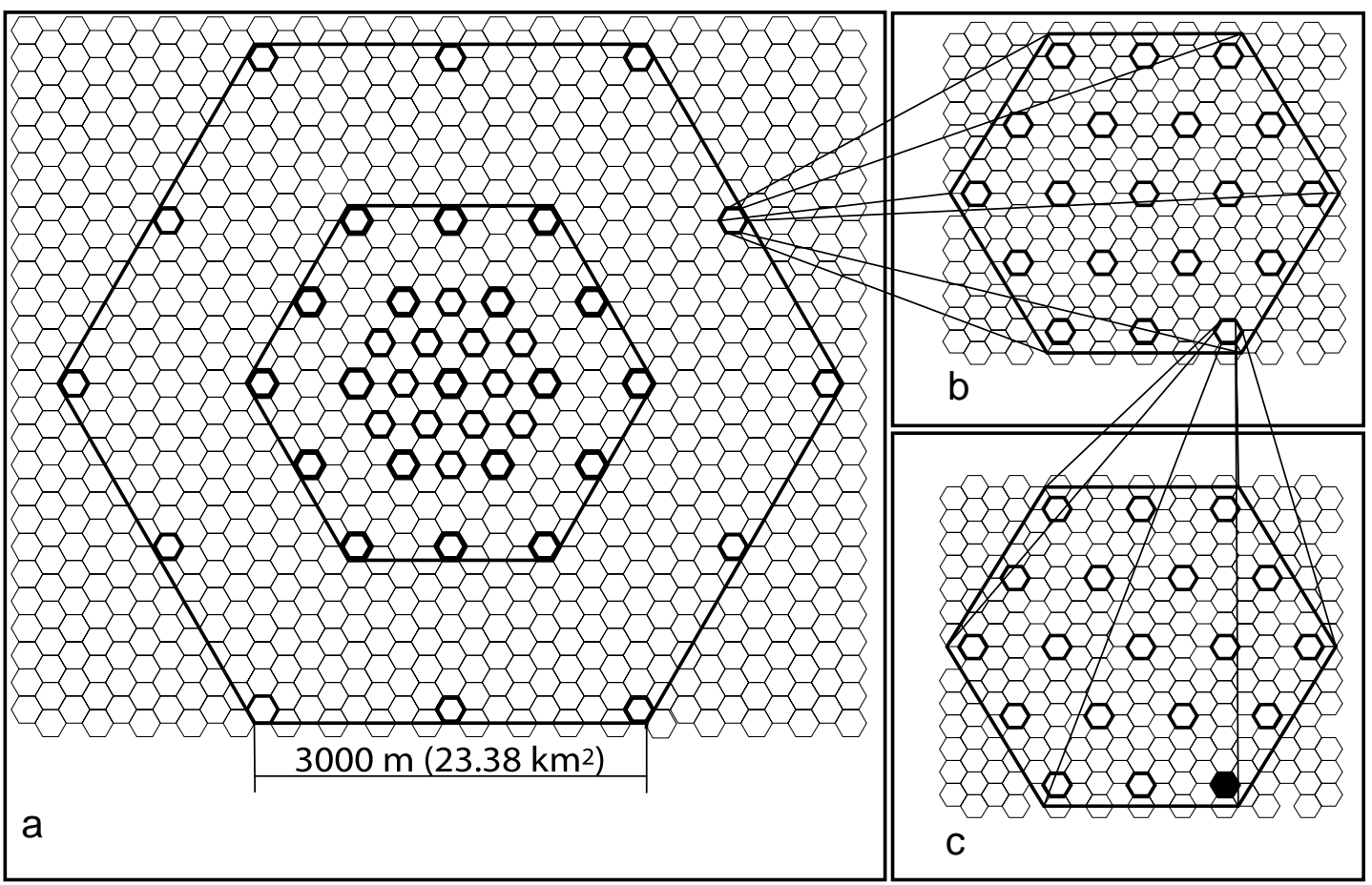

Fig. 2- Nested sampling design. Inside the investigation area (a: side length $3000 \mathrm{~m}$, area $23.38 \mathrm{~km}^{2}$ ) plots are arranged in a regular hexagonal grid. Inside each plot (b: side length $120 \mathrm{~m}$, area $3.74 \mathrm{ha}$ ), sample plots are located, and each of these contains sub-plots (c). The sample plots have a side length of $8 \mathrm{~m}\left(\right.$ area $\left.166 \mathrm{~m}^{2}\right)$. One side of the sub-plot measures $0.6 \mathrm{~m}$, area is about $0.94 \mathrm{~m}^{2}$ ). One of the sub-plots is filled black.

because of its importance as a structural element of the field layer. It is one of the few species in the study area that can be found with cover values (after Braun-Blanquet, 1964) other than ' + ' or ' $r$ '. It is a perennial member of the Asphodelaceae with straight, succulent leaves and considerable clonal growth. Due to its growth habit it provides shade and strongly influences microclimatic conditions for other plants. In general, animals avoid this plant, resulting in Asphodelus carpets. These do not form a closed canopy, thus allowing ephemerals and annuals to grow where they are protected from grazing, direct sunlight and drought.

The ropes that were used to mark out the plots are segmented (alternating red and white every $20 \mathrm{~cm}$ with additional marks at every meter and every two meters) to facilitate recording. For each rope the proportion covered by a certain feature was assessed and recorded in a checklist (Fig. 3). The cover value for a certain feature on the sample plot was later calculated automatically inside the database by summing up the proportions on the twelve lines. For analysis regarding the quality of the line-intercept method we only used the cover values of the bushes and trees because these matched the sketched features. The sketching of the proportion of open soil, open stones and
Asphodelus microcarpa would have been very time consuming and too elaborate to undertake.

Figure 4 shows the steps in the preparation of the sketches. These were scanned and georeferenced in $\operatorname{ArcMAP}^{\circledR}$ (part of the $\operatorname{ArcGIS}^{\circledR}$ package from ESRI, which was also used for the following procedures). The elements recorded were digitised separately for each species and sample plot. All features occurring fully or partly inside a plot were mapped. In the data-table belonging to the created shape-file (.shp) further information (vegetation layer, height, etc.) was assigned to the digitised features to enable later queries. The shape files were then merged into a single file. Due to the implementation of a global identifier, it is still possible to separate the shapes by their sample plot code, vegetation layer, height and species.

All parts of the shapes outside the hexagonal plot were cut off at the edges so that only those parts inside were included in further analysis. As we were interested in the cover of bushes and trees regardless of species identity we combined the species and ordered them in relation to their presence in the vegetation layers. Based on this, the polygons of a sample plot were combined into one single shape, which allowed the calculation of a single value per sample plot for the area covered by a certain feature (bush or tree). 


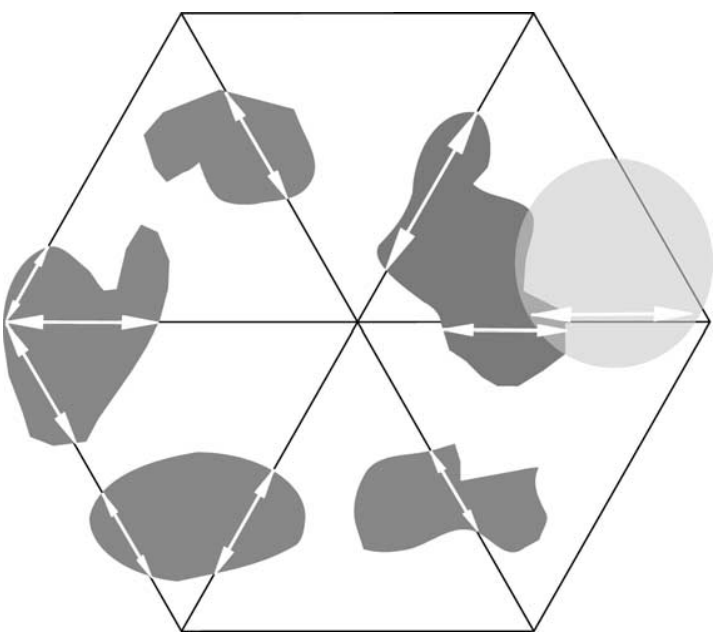

Fig. 3-Using the marking ropes for assessing data on structure or species through the implementation of the line-intercept method: The ropes are segmented for more efficient working: general division is red/background every $20 \mathrm{~cm}$. Background changes every $2 \mathrm{~m}$ plus $1 \mathrm{~m}$ markers and a centre marker (not displayed).

\section{FREQUENCY DATA VERSUS PRESENCE-ABSENCE DATA}

During sampling in 2005 frequency data were obtained to examine whether this changed the response of the calculated similarity indices (or distance measures respectively) in relation to other variables. Data were recorded in fifteen sample plots belonging to three structural types so that every type is represented by five replicates. The structural types were defined on the basis of shrub and tree cover data from previous years' recordings and can be defined as:

- 'steppe-like '(no bushes or trees)

- 'scattered bushes' (bush-cover 2\%-30\%, treecover $\leq 2 \%)$

- 'maquis-like' ( $>30 \%$ of bush cover, $\leq 7 \%$ of tree cover)

- 'park-like' ( $>20 \%$ of tree-cover, $\leq 5 \%$ of bush cover)

- 'forest-like' (tree-cover $>40 \%$, bush-cover $5 \%-35 \%)$

- 'mosaic' (bush-cover $>20 \%$, tree-cover $>20 \%$ )

- the remainder, where none of the above conditions was met.

Only sample plots from the structural types 'steppe-like', maquis-like' and 'bush-like' were sampled because significant differences were anticipated between them. The sample plots were chosen randomly so that at least one of the five in every structural type was sampled in both of the previous years' of study and two each of the others were sampled in 2003 and in 2004 respectively. This allowed temporal changes to be investigated.
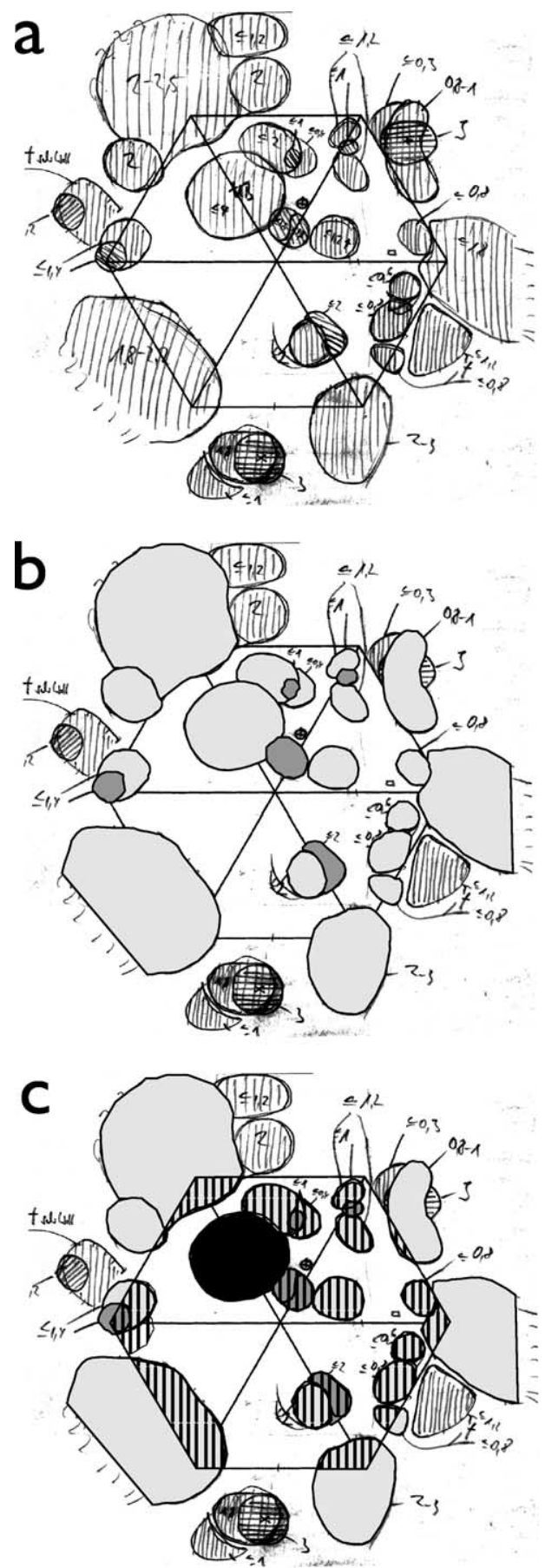

Fig. 4-Sketch preparation. The sketches were scanned from paper (a), then all features inside or intersecting the hexagonal plot were digitised (including species identity). In (b) and (c) the light grey symbolises Quercus rotundifolia and grey, the Juniperus oxycedrus bushes. c) shows that the digitised features were then combined and ordered according to their layer (bush: black hash, tree: black fill) and cut off at the edges of the hexagon.

To obtain frequencies the six triangles forming the hexagonal plot were sampled separately so that the occurrence of a species in 
all of the triangles would be represented in a frequency value of six. Species data were stored in the database as they were recorded. For further analysis data were aggregated into a species list containing the names of every species found in a sample plot plus their frequency, which was calculated automatically from the data. With the software-application $\mathrm{PC}-\mathrm{Ord}{ }^{\circledR} \quad$ (McCune and Mefford 1999) several distance measures (BrayCurtis, Relative Sørensen, Jaccard-distance, chi ${ }^{2}$ distance) were calculated. A very similar species list containing the names of the species recorded in sample plots but without frequency information was used to obtain similarities (Sørensen, Jaccard, Whittaker and several others; see Koleff et al. 2003 for a comprehensive review of similarity indices).

All existing similarity measures use the same variables. To be independent of the similarity measures offered in existing Software (e.g. PC$\operatorname{Ord}^{\circledR}$, SPSS $^{\circledR}$ ) a perl-script was used to apply a search algorithm that identifies the pairs of sample plots to be compared. It searches a file containing the coordinates and names of the sample plots. With the information of each possible pair of sample plots, another file, containing the species list in database format, is searched for all the species recorded in these sample plots. The values of the variables a, b, c, and $d$ that are used in similarity indices are determined on a text-based comparison. These variables represent:

a. species found in both of the sample plots (shared species)

b. species found only in one of the compared sample plots

c. species found in the other of the two compared sample plots

d. species found only in the rest of the data set.

Through a simple count algorithm the numbers of species in each variable for each sample plot pair are calculated and written to a file containing all the information needed to calculate similarity indices. It is imported into a database file where many of the existing similarity indices are stored as formulae. As the data are imported all the similarities for all given pairs and formulae are calculated.

The calculated similarity indices were then related to other variables (such as vegetation structure or disturbance). The correlation cannot be calculated directly with variables recorded in the plot because the similarities represent the relationship of attributes (presence of plant species) in pairs of plots. Therefore, the plots were compared (using distance measures because of the quantitative nature of the data) based on other variables (e.g. $\mathrm{pH}, \mathrm{C} / \mathrm{N}$, conductivity, structure, and disturbance). The distance values obtained were then evaluated regarding their correlation to the distances and similarities based on species data. Several distance measures and similarity indices have been applied to the data, using standard formulae (Jaccard 1912; Sørensen 1948; Bray and Curtis 1957).

\section{RESULTS}

\section{ASSESSING STRUCTURES}

The cover values derived from the line-intercept method and from the sketches were compared and correlated. The results show that there is very good correlation (Pearson). Figure 5 displays the scatter plots of the correlation for bush and tree cover values respectively. The cover values based on line intercept, and the sketches are highly significantly correlated. The correlation of the bush-cover-values is slightly better $\left(R^{2}=0.78\right.$, $r=0.88^{\star \star \star},\left(^{\star \star \star}\right.$ indicates significant at the $p<$ 0,001 level) than the correlation of the treecover values $\left(R^{2}=0.70, r=0.84^{\star \star \star}\right)$. This could be due to the crown projection, which may have been imprecise especially in the case of taller trees. In addition we calculated the Bray-Curtis distances between the values. This allows for the combined evaluation of the proximity of the values for bush and tree cover with the two different methods. All the calculated values were combined into the box plot in Fig. 6. The distances are mostly very small (see the Whiskers position) as are the median and standard deviations (thick black line and box), indicating that the values for the structural variables obtained with the two different methods are very close to each other.

\section{FREQUENCY DATA VERSUS PRESENCE-ABSENCE DATA}

The calculated similarities (Sørensen, based on presence-absence data) and distances (BrayCurtis, based on frequency-data) show a very close relation if plotted against each other (Fig. 7a, $\left.r=-0.92^{\star \star \star}, \quad R^{2}=0.85\right)$, indicating that presence-absence data suggest a similar vegetation structure to frequency data. The relationship is negative because of the nature of the measures one measuring dissimilarity (or distance) and the other measuring similarity. Regarding their relation to other variables, they both show the strongest correlation with the dissimilarity of structures. This was anticipated from other work (not described here), where we found that the similarity of vegetation based on presence-absence data showed a stronger correlation with dissimilarity of structure than with the dissimilarity of other factors, such as disturbance, soil parameters, aspect, or 

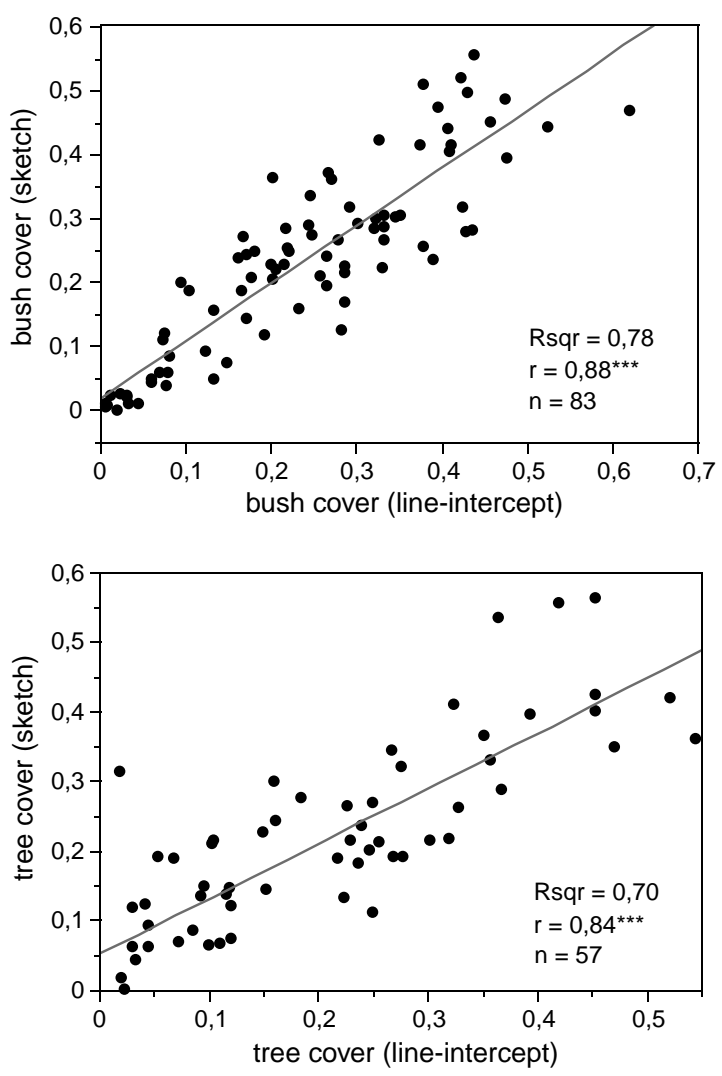

Fig. 5-Correlation between the values derived from the assessment of structures via the line-intercept method and the sketches based on bush and tree cover values respectively. ' $r$ ' is the Pearson correlation coefficient; the line is the regression line. ' $n$ ' is less for tree cover values because not all plots incorporated in the analysis actually had trees.

slope. The Bray-Curtis distances $\left(R^{2}=0.35, r=\right.$ $\left.0.59^{\star \star \star}\right)$ perform moderately better in this regard than the Sørensen similarities $\left(R^{2}=0.26, \quad r=\right.$ $-0.51^{\star \star \star}$, see Fig. $7 \mathrm{~b}$ and $\left.7 \mathrm{c}\right)$, suggesting a slightly better relationship with frequency data compared to presence-absence data. Overall, these analyses suggest that recording presenceabsence results in only a slight reduction in useful information compared to the more time consuming measurements of frequency.

\section{DISCUSSION}

\section{ASSESSING STRUCTURES}

The comparison of the structural variables recorded with the line-intercept method and with the sketches reveals a very close relationship between the respective values. This is true regardless of the technique used to compare the two methods. This indicates that the recording of

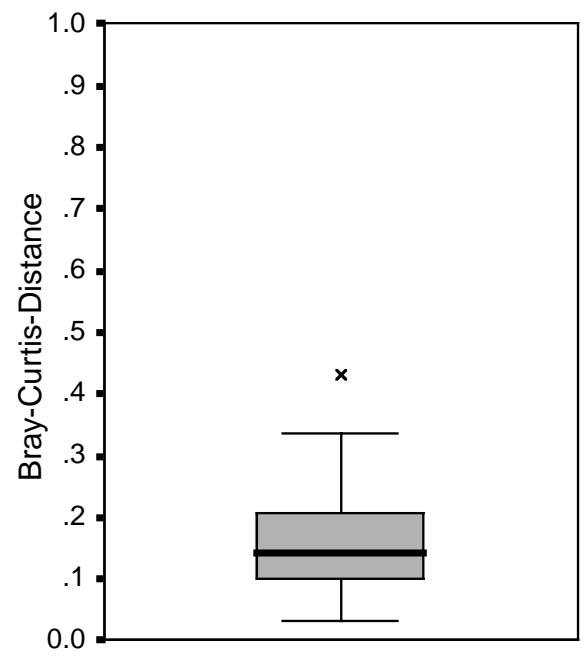

Fig. 6-Distances (dissimilarity) between the values for the cover of trees and bushes combined derived with lineintercept method and from the sketches $(n=57)$. The thick line represents the median, the box represents the interquartile range. Whiskers are extremes. The ' $x$ ' is an outlier.

structural features in the hexagonal plot with the line-intercept method is a very reliable and efficient method to quantitatively characterise vegetation structure. It can be completed in just $20 \%$ of the time needed for the sketches (all working steps summarised), which makes it a realistic and labour-saving alternative. It also provides possibilities elsewhere. In a recent study in a Tundra-ecosystem, where micro-relief has an important ecological function (e.g. Matveyeva 1988; Walker 1995; Callaghan et al. 2001), Rettenmaier (2004) showed that it is also possible to assess surface roughness using a slightly adapted hexagonal plot sampling methodology. The ratio between the length of a rope following all the surface bumps and hollows to the direct distance was successfully used to quantify surface roughness. In this case the methodology also allowed for the assessment of the proportions of bare fine substrate, open stones, vegetation-covered stones, small ponds and boggy depressions.

As the ropes cross the plot through the centre and at the perimeter, the structural variables are assessed systematically and exactly. They are valid at the sampling location on which they were recorded even though there might be some auto-correlation because of the geographical proximity of the lines (which may be considered as short transects). The sketches that were made during the first field season provide a more exact basis for structural data but require much more work both in the field and in the lab. As we wanted to provide a methodology that minimises effort while giving sufficiently 

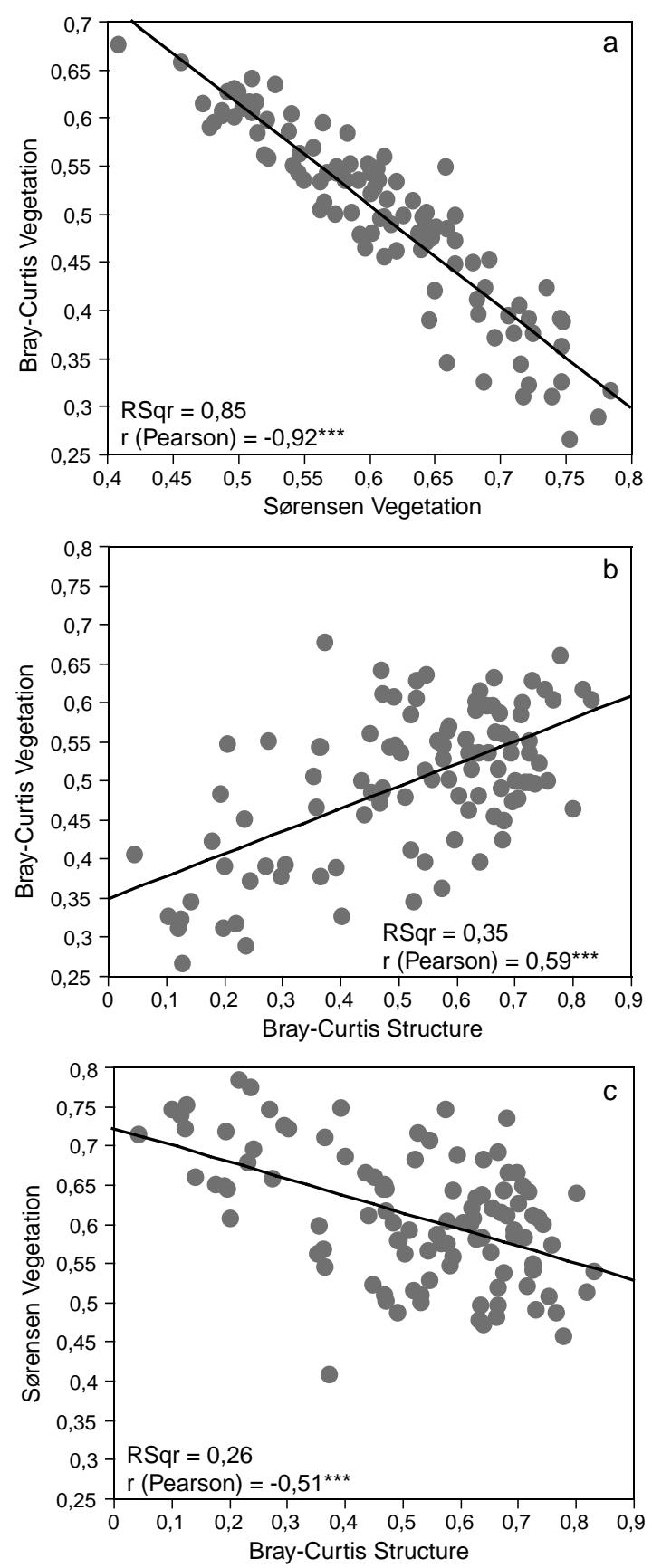

Fig. 7-Frequency versus presence-absence data: (a) The distance values (Bray-Curtis) plotted against the similarity values (Sørensen) reveals close relation between these different methods; (b) Bray-Curtis distance on structural variables plotted against BrayCurtis distance based on frequency species data; (c) the Bray-Curtis distances based on structural variables plotted against Sørensen similarity based on presence-absence species data.

accurate data on biodiversity and environment, the line-intercept approach on the hexagonal plot seems to be a very efficient and easily applied method.

\section{FREQUENCY VERSUS PRESENCE-ABSENCE DATA}

We have shown that the results obtained on the basis of frequency data and presence-absence data respectively differ only slightly regarding the correlation between similarity (or dissimilarity) of vegetation and distance values based on other environmental variables. However, additional information is obtained if quantitative data on species are used. Furthermore we have to admit that the six-triangle method produces very coarse frequency values. It is very likely that even more information could be obtained through a finer resolution of frequency values, although this would increase the effort required. We also found that for the methodology presented here the additional information obtained using frequency values at a finer resolution does not reflect the increase in effort required for data recording (Beierkuhnlein 1999; Neßhöver 1999; Retzer 1999), which is much greater compared to the assessment of presence-absence data.

Similar arguments apply in regard to cover values. Since one of our major objectives is the development of a comprehensive and reproducible method to assess spatial patterns of biodiversity, we avoided using cover values because they are often found to be highly variable. This is because they depend on the recorder, time of day, vegetation height and other factors (Dierschke 1994; MuellerDombois and Ellenberg 1974). Even though subjective methods might be as precise as objective methods under certain circumstances (Floyd and Anderson 1987; Dethier et al. 1993; Kent and Coker 1994; Brakenhielm and Qinghong 1995) we think that it is more appropriate to use very simple methods, especially when implementing long term monitoring. If a lot of sampling must be done in as short a time as possible-as is often the case with systematic sampling grids - it is better to use presenceabsence data instead, particularly if they compare well with other, much more elaborate and timeconsuming approaches.

\section{CONCLUSIONS}

The systematic sampling on a hexagonal grid is a good way to reveal patterns of biodiversity and to relate them to other environmental variables. Here we presented results showing that hexagonal plots provide several advantages. However, it is most important to state that the patterns that emergeare dependent on the scale of observation. By deciding on the sampling design we, as scientists, predetermine which patterns are found. Consequently, it is crucial to accurately define the scope 
and the purpose of the studies trying to reveal and explain spatio-temporal patterns in nature. Preliminary investigations can be used to determine the 'right' plot and grid shape, but problems persist because the size of a plot and the distance to its neighbours are not necessarily linked, although both determine the described patterns. We propose a spatially and temporally nested design to investigate the ecological factors shaping spatial patterns in nature. The hexagonal grid approach has the potential to serve as a tool for a rapid, reliable and comprehensive assessment of biodiversity.

\section{ACKNOWLEDGEMENTS}

We would like to thank our field colleagues Tonia Lerche, Roman Hein, and Andreas Gohlke and the Ministére des Eaux ets Forets de Maroc for their support. The many useful comments on the manuscript of three anonymous reviewers are gratefully acknowledged. The work is part of a project funded by the German Science Foundation (DFG, BE2192/5-1-3).

\section{REFERENCES}

Addicott, J.F., Aho, J.M., Antolin, M.F., Padilla, D.K., Richardson, J.S. and Soluk, D.A. 1987 Ecological neighborhoods: Scaling environmental patterns. Oikos 49, 340-6.

AG Boden 1996 Bodenkundliche Kartieranleitung, Hannover. E. Schweizerbart'sche Verlagsbuchhandlung.

Allan, J.D., Brenner, A.J., Erazo, J., Fernandez, L., Flecker, A.S., Karwan, D.L., Segnini, S. and Taphorn, D.C. 2002 Land use in watersheds of the Venezuelan Andes: a comparative analysis. Conservation Biology 16, 527-38.

Araújo, M.B. 1999 Distribution patterns of biodiversity and the design of a representative reserve network in Portugal. Diversity and Distributions 5, 151-63.

Austin, M.P. 1981 Permanent quadrats: An interface for theory and practice. Vegetatio 46, 1-10.

Austrheim, G., Gunilla, E., Olsson, A. and Grontvedt, E. 1999 Land-use impact on plant communities in semi-natural sub-alpine grasslands of Budalen, central Norway. Biological Conservation 87, 36979.

Ayres, M.P. and Lombardero, M.J. 2000 Assessing the consequences of global change for forest disturbance from herbivores and pathogens. Science of the Total Environment 262, 263-86.

Bednekoff, P.A. 2001 A baseline theory of biodiversity and ecosystem function. Bulletin of the Ecological Society of America 82, 205.

Beierkuhnlein, C. (ed.) 1999 Rasterbasierte Biodiversitätsuntersuchungen in nordbayerischen Landschaftsräumen . Bayreuth. BITÖK.
Bermejo, V., Gimeno, B.S., Granados, I., Santamaria, J., Irigoyen, J.J., Bermejo, R., Porcuna, J.L. and Mills, G. 2002 Investigating indices to explain the impacts of ozone on the biomass of white clover (Trifolium repens L. cv. Regal) at inland and coastal sites in Spain. New Phytologist 156, 43-55.

Brakenhielm, S. and Qinghong, L. 1995 Comparison of field methods in vegetation monitoring. Water, Air and Soil Pollution 79, 75-87.

Braun-Blanquet, J. 1964 Pflanzensoziologie. Grundzüge der Vegetationskunde. Wien. Springer.

Bray, J.R. and Curtis, J.T. 1957 An ordination of the upland forest communities in southern Wisconsin, 32549. Ecological Monographs no. 27.

Callaghan, T.V., Matveyeva, N.V., Chernov, Y. and Brooker, R. 2001 Arctic ecosystems. In S.A. Levin (ed.), Encyclopedia of Biodiversity, 231-40. San Diego. Academic Press.

Colbach, N., Dessaint, F. and Forcella, F. 2000 Evaluating field-scale sampling methods for the estimation of mean plant densities of weeds. Weed Research 40, 411-30.

Cole, R.G., Healy, T.R., Wood, M.L. and Foster, D.M. 2001 Statistical analysis of spatial pattern: a comparison of grid and hierarchical sampling approaches. Environmental Monitoring and Assessment 69, 85-99.

Constable, J.V. H., Litvak, M.E., Greenberg, J.P. and Monson, R.K. 1999 Monoterpene emission from coniferous trees in response to elevated $\mathrm{CO}_{2}$ concentration and climate warming. Global Change Biology 5, 252-67.

Cracraft, J. 1992 Explaining patterns of biological diversity: integrating causation at different spatial and temporal scales. In N. Eldredge (ed.), Systematics, ecology and the biodiversity crisis, 59-76. New York. Columbia University Press.

Crist, P.J., Kohley, T.W. and Oakleaf, J. 2000 Assessing land-use impacts on biodiversity using an expert systems tool. Landscape Ecology 15, 47-62.

de Vries, W., Vel, E., Reinds, G.J., Deelstra, H., Klap, J.M., Leeters, E.E.J.M., Hendriks, C.M. A., Kerkvoorden, M., Landmann, G. and Herkendell, J. 2003 Intensive monitoring of forest ecosystems in Europe: 1. Objectives, set-up and evaluation strategy. Forest Ecology and Management 174, 77-95.

De'ath, G. 1999 Extended dissimilarity: a method of robust estimation of ecological distances from high beta diversity data. Plant Ecology 144, 191-9.

Dethier, M.N., Graham, E.S., Cohen, S. and Tear, L.M. 1993 Visual versus random-point percentage cover estimations: 'objective' is not always better. Marine Ecology Progress Series no. 96, 93-100.

Dierschke, H. 1994 Planzensoziologie. Grundlagen und Methoden. Stuttgart. Verlag Eugen Ulmer.

Everson, T.M., Clarke, G.P. Y. and Everson, C.S. 1990 Precision in monitoring plant species composition in montane grasslands. Vegetatio $\mathbf{8 8}, 135-41$.

Floyd, D.A. and Anderson, J.E. 1987 A comparison of three methods for estimating plant cover. Journal of Ecology 75, 221-8.

Goodall, D.W. 1952 Some considerations in the use of point quadrats for theanalysis of vegetation. Australian Journal of Scientific Research, Series B 5, $1-41$ 


\section{BIOLOGY AND ENVIRONMENT}

Gottfried, M., Pauli, H. and Grabherr, G. 1998 Prediction of vegetation patterns at the limits of plant life: A new view of the alpine-nival ecotone. Arctic and Alpine Research 30, 207-21.

Grime, J.P. 1998 Benefits of plant diversity to ecosystems: immediate, filter and founder effects. Journal of Ecology 86, 902-10.

Hannah, L., Midgley, G.F. and Millar, D. 2002 Climate change-integrated conservation strategies. Global Ecology and Biogeography 11, 485-95.

Hart, M.M., Reader, R.J. and Klironomos, J.N. 2001 Biodiversity and ecosystem function: alternate hypotheses or a single theory? Bulletin of the Ecological Society of America 82, 88-90.

Hättenschwiler, S. and Körner, C. 2003 Does elevated $\mathrm{CO}_{2}$ facilitate naturalization of the nonindigenous Prunus laurocerasus in Swiss temperate forests? Functional Ecology 17, 778-85.

Higgins, M.A. and Ruokolainen, K. 2004 Rapid tropical forest inventory: a comparison of techniques based on inventory data from western Amazonia. Conservation Biology 18, 799-811.

Jaccard, P. 1912 The distribution of the flora of the alpine zone. New Phytologist 11, 37-50.

Kent, M. and Coker, P. 1994 Vegetation description and analysis: a practical approach. London. Publisher.

Kipfmueller, K.F. and Baker, W.L. 1998 A comparison of three techniques to date standreplacing fires in lodgepole pine forests. Forest Ecology and Management 104, 171-7.

Kluth, C. and Bruelheide, H. 2004 Using standardized sampling designs from population ecology to assess biodiversity patterns of therophyte vegetation across scales. Journal of Biogeography 31, $363-77$.

Koleff, P., Gaston, K.J. and Lennon, J.J. 2003 Measuring beta diversity for presence-absence data. Journal of Animal Ecology 72, 367-82.

Körner, C. 2003 Carbon limitation in trees. Functional Ecology 91, 4-17.

Krishnamani, R., Kumar, A. and Harte, J. 2004 Estimating species richness at large spatial scales using data from small discrete plots. Ecography 27, $637-42$.

Leps, J. 1992 How reliable are our vegetation analyses. Journal of Vegetation Science 3, 119-24.

Lister, A.J., Mou, P.P., Jones, R.H. and Mitchell, R.J. $2000 \quad$ Spatial patterns of soil and vegetation in a 40-year-old slash pine (Pinus elliottii) forest in the Costal Plain of South Carolina, U.S.A. Canadian Journal of Forest Research-Revue Canadienne de Recherche Forestiere 30, 145-55.

Matveyeva, N.V. 1988 The horizontal structure of tundra communities. In H.J. During, H.J.A. Werger and H.J. Williams (eds), Diversity and pattern in plant communities, 59-66. Den Haag. SPB Academic Publishing.

McCune, B. and Mefford, M.J. 1999 Multivariate analysis of ecological data. Glenedon Beach, Oregon. MjM Software.

Mueller-Dombois, D. and Ellenberg, H. 1974 Aims and methods of vegetation ecology. New York. Wiley.
Nekola, J.C. and White, P.S. 1999 The distance decay of similarity in biogeography and ecology. Journal of Biogeography 26, 867-78.

Neßhöver, C. 1999 Charakterisierung der Vegetationsdiversität durch funktionelle Attribute von Pflanzen - am Beispiel eines Landschaftsausschnittes der Nördlichen Frankenalb. In C. Beierkuhnlein (ed.), Rasterbasierte Biodiversitätsuntersuchungen in nordbayerischen Landschaftsräumen, 1-114. Bayreuth. BITÖK - Bayreuther Institut für terrestrische Ökosystemforschung.

Olsvig-Whittaker, L. 1988 Relating small-scale vegetation patterns to the environment. In H.J. During, H.J.A. Werger and H.J. Williams (eds) Diversity and pattern in plant communities, 87-94. Den Haag. SPB.

Pitkänen, S. 1998 The use of diversity indices to assess the diversity of vegetation in managed boreal forests. Forest Ecology and Management 112, 121-37.

Rettenmaier, N. 2004 Räumliche Muster der Biodiversität in der skandinavischen Tundra. Unpublished diploma thesis, Universität Bayreuth, Lehrstuhl für Biogeografie.

Retzer, V. 1999 Charakterisierung und Vergleich der Vegetationsdiversität zweier KulturlandschaftenUntersuchungen anhand einer systematischen Rastermethode in Frankenalb und Fichtelgebirge. In C. Beierkuhnlein (ed.), Rasterbasierte Biodiversitätsuntersuchungen in nordbayerischen Landschaftsräumen, 117-206 S. Bayreuth. BITÖKBayreuther Institut für terrestrische Ökosystemforschung.

Richerson, P.J. and Lum, K.-L. 1980 Patterns of plant species diversity in California: relation to weather and topography. The American Naturalist 116, 504-36.

Sala, O.E., Chapin, F.S., Armesto, J.J., Berlow, E., Bloomfield, J., Dirzo, R., Huber-Sanwald, E., Huenneke, L.F., Jackson, R.B., Kinzig, A., Leemans, R., Lodge, D.M., Mooney, H.A., Oesterheld, M., Poff, N.L., Sykes, M.T., Walker, B.H., Walker, M. and Wall, D.H. 2000 Biodiversity - global biodiversity scenarios for the year 2100. Science 287, 1770-4.

Schulze, E.-D. and Mooney, H.A. (eds) 1993 Biodiversity and ecosystem function. Berlin, Heidelberg. Springer.

Singer, M.C., Stefanescu, C. and Pen, I. 2002 When random sampling does not work: standard design falsely indicates maladaptive host preferences in a butterfly. Ecology Letters 5, 1-6.

Sørensen, T. 1948 A method of establishing groups of equal amplitude in plant sociology based on similarity of species content. Biologiske Skrifter 5, $1-34$.

Tilman, D. and Elhaddi, A. 1992 Drought and biodiversity in grasslands. Oecologia 89, 257-64.

Traxler, A. 1998 Handbuch des vegetationsökologischen Monitorings. Methoden, Praxis, angewandte Projekte. Teil A - Methoden. Wien. Umweltbundesamt.

Tüxen, R. 1972 Kritische Bemerkungen zur Interpretation pflanzensoziologischer Tabellen. In E. van der Maarel and R. Tüxen (eds), Grundfragen 


\section{Vegetation Assessment with Hexagonal Grids}

und Methoden in der Pflanzensoziologie, 168-82. Den Haag. Junk.

Valdés, B., Rejdali, M., Achhal EL Kadmiri, A., Jury, J.L. and Montserrat, J.M. (eds) 2002 Checklist of vascular plants of $\mathrm{N}$ Morocco with identification keys. Madrid. Consejo Superior de Investigaciones Cientificas. van der Maarel, E. 1976 On the establishment of plant community boundaries. Berichte der Deutschen Botanischen Gesellschaft 89, 415-43.

Walker, M.D. 1995 Patterns and causes of arctic plant community diversity. In F.S. Chapin and C. Körner (eds), Arctic and Alpine biodiversity: patterns, causes and ecosystem consequences, 3-20. Berlin. Springer. 